\title{
Review Paper: Evaluation of Balance in Patients With Knee Osteoarthritis Compared to Healthy Controls
}

\author{
Tahere Rezaeian$^{1}$, Iraj Abdollahi ${ }^{1^{*}}$, Mahnaz Emami ${ }^{1}$
}

1. Department of Physiotherapy, University of Social Walfare and Rhabilitation Sciences, Tehran, Iran.

Citation: Rezaeian T, Abdollahi I, Emami M. Evaluation of Balance in Patients With Knee Osteoarthritis Compared to Healthy Controls. Physical Treatments. 2015; 5(3):119-126.

Article info:

Received: 04 Mar. 2015

Accepted: 11 Jul. 2015
Keywords:

Knee osteoarthritis, Postural balance, Knee pain

\begin{abstract}
A B S T RA C T
Purpose: Over the past 20 years, the center of pressure (COP) has been commonly used as an index of postural stability in standing. While many studies investigated COP excursions in patients with knee osteoarthritis and healthy individuals, no comprehensive analysis of the differences in their postural sway pattern exists. The present study aimed to review the previously published studies concerning differences in COP pattern performance in patients with knee osteoarthritis compared to healthy controls.

Methods: A literature search was performed on articles published from 1995 to 2014 using Elsevier, Science Direct, ProQuest, Google scholar, PubMed, and Medline databases. The search keywords were "knee Osteoarthritis", "healthy people", "postural stability", "balance", and "force plate".

Results: Five articles were selected according to the inclusion criteria of the study. There was a wide variation among studies in terms of methodology, sample size, and procedure. All available studies investigated postural control in patients with knee osteoarthritis. According to the results, 3 study showed that patients group reported more postural sway and less stability compared to healthy group with both eyes open and closed, especially with eyes closed. However, in 2 other studies, no difference was observed in the parameters of the balance between patients and healthy people. So that COP displacement was similar in patients compared to healthy people.

Conclusion: The results demonstrate that patients with knee osteoarthritis compared to healthy people show more postural instability. This difference was more pronounced under eyes closed condition. The possible mechanism in association with balance alteration can be pain inhibition, loss of proprioception, and muscle weakness.
\end{abstract}

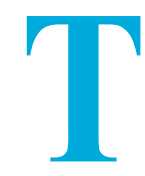

\section{Introduction}

he body fluctuation can be measured by considering the changes in the level of support and pressure which are exerted upon force plate. The center of pressure (COP) is the point, which will be on tip toe if the pressure of the body is focused in one point. These fluctuations are caused by many factors such as inherent noise

\section{* Corresponding Author:}

Iraj Abdollahi, PhD

Address: Department of Physiotherapy, University of Social Walfare and Rhabilitation Sciences, Koodakyar Ave., Daneshjoo Blvd., Evin, Tehran, Iran Phone: +98 (912) 2181706

E-mail: irajabdollahi@hotmail.com 
in human neuromotor system. Many uncontrollable factors may help balance system disorder such as loss or weakness of sensory-motion system caused by aging or neurological or musculoskeletal system impairment such as osteoarthritis $[1,3]$.

Knee osteoarthritis can be defined as joint dysfunction that changes the anatomy of the joints, particularly destruction of cartilage and bone deformities. However, in most cases there is no sign of inflammation with joint destruction. Various pathological, physiological, metabolic, and inflammatory factors are involved in the etiology of the disease which aging and mechanical factor are among the most common ones [4].

The disease has a gradual and progressive development. In middle-aged people and those who are younger than 50 years, the prevalence of the disease is almost equal in both sexes. But in 50 years old people, the prevalence in women is more, especially in the joints of hands and knees. The possible reason for this difference relates to hormonal changes and immobility. It is approximately estimated that $30 \%$ of men and $33 \%$ of women aged $69-60$ years suffer from knee pain and osteoarthritis.

Symptoms include pain, joint stiffness following by immobility, reducing motion range of the joint, and unusual sound of joints. Radiological changes include erosion and degradation of articular cartilage, loss of joint space, sclerosis in the bone under cartilage and deformity [5].

Another disorders include inability in climbing up stairs, increasing pain by exercising, stumbling in walking, deformity of the knee in virus-like shape and decreasing the balance of patient. In this illness, quadriceps muscle strength and aerobic capacity of the patient reduce. Also, joint proprioception, balance, and coordination decrease and accordingly stability of knee joint decreases.

There are different theories about the effect of knee osteoarthritis on postural stability. Ideally, the body should have the ability for quick shift of COP, in response to changes in the center of gravity and moving to the opposite side for keeping balanced. Degenerative changes in knee joints cause mismatching in joints and increasing the postural fluctuations. Hassan believed that knee pain is one of the factors causing postural fluctuations in people who suffer from osteoarthritis [9]. The result indicated that postural stability in these people can be influenced by muscle weakness, loss of proprioception, obesity, and loose joints. Aging by itself can be followed by neuromuscular changes such as low proprioception and muscle weakness which have a negative influence on postural balance [9].
On the other hand, this mechanism may be associated with changes in the balance as well as pain control. The results revealed that the pain can increase presynaptic inhibition of afferent muscles, modulate the center of the muscle spindles proprioception, cause long-lasting latency, and decrease muscle spindles feedback. These changes can decrease muscle control and increase postural fluctuations. However, the association between postural disorders and knee osteoarthritis is unknown [9]. Previous research was concerned on different parameters of postural fluctuations in these patients, including variables related to COP [3, 10-16] and estimates of vertical displacement of the center of gravity [18].

This review tries to evaluate balance performance among people with knee osteoarthritis and healthy subjects with regard to mentioned mechanisms. Despite a lot of research in this area, there is no review on how to examine the effect of knee osteoarthritis on the pattern of pressure. The present study aimed to systematically review the literature and explore the differences in pressure patterns between patients with knee osteoarthritis and healthy individuals.

\section{Materials and Methods}

This systematic study was done according to preferred reporting items for systematic review and meta-analysis (PRISMA). It was approved by Ethics Committee of the University of Welfare and Rehabilitation Sciences. In order to evaluate papers and articles related to postural stability in patients with knee osteoarthritis, we searched in databases of Elsevier, Science Direct, ProQuest, Google scholar, PubMed, and Medline and found related articles published from 1995 to 2014. Research strategy was according to PRISMA, by considering items such as study subjects, intervention, comparison, outcomes, and study design.

These keywords have been used in the search; "osteoarthritis and healthy people," "balance", "postural stability", and "force plate". Some references in the available literature were also reviewed.

\section{Inclusive and exclusive criteria for study selection}

Searching for available studies has been done to find related articles. The inclusive criteria for selecting articles were as follows:

- The studies which have been published in English or Persian.

- The studies which have been available in full-text form. 
- The studies that reviewed measuring the COP of people suffering from osteoarthritis with static tasks standing on both feet on force plate comparing to healthy subjects.

For the purpose of this study, we defined osteoarthritis as feeling pain originated from musculoskeletal system without neurological symptoms or structural damage due to serious trauma or pathology like cancer or infection.

There is no limit on demographic data. However, we disregard those studies, which include dynamic tasks like walking, leaping on one leg, standing on one leg on force plate, also non-English or non-Persian studies, and those ones which did not compare healthy subjects with the patient ones.

\section{Data collection and methodology}

Two research critics (PhD students in physiotherapy and physical therapy) independently selected studies from various databases. Distinctive ideas were reviewed and the final agreement was reached. Studies are selected if they meet 3 criteria for inclusion. If the title and abstract were not clear, the paper would be examined thoroughly
(Figure 1). The two critics also read the entire report and a meeting was held for final agreement on distinctive ideas of critics. Articles were selected according to Critical Appraisal Skills Programme (CASP). The checklist CASP was used for qualitative evaluation of clinical trials. The results of CASP checklist have been summarized in Table 2. The results will be confirmed positively if the writers conclude postural control was examined in static mode with two legs standing on force plate in patients suffering from osteoporosis, and confirmed negatively if vice versa.

Technical evaluation revealed 6 individual items related to distinctions between patients suffering from osteoarthritis and healthy subjects. Examined items for designing the experiments were as follows: 1) Demographic information, 2) The duration of sampling, 3) The number of retesting, 4) Terms of vision (eyes open and closed), 5) Standing, and 6) The type of the plate form.

According to the explanations given in the first stage, 283 articles were selected and evaluated. After reviewing the titles, 153 articles were identified and included in the second phase of the qualitative abstracts evaluation. Articles were excluded if they included dynamic task, not using force plate, the patients were standing on one foot

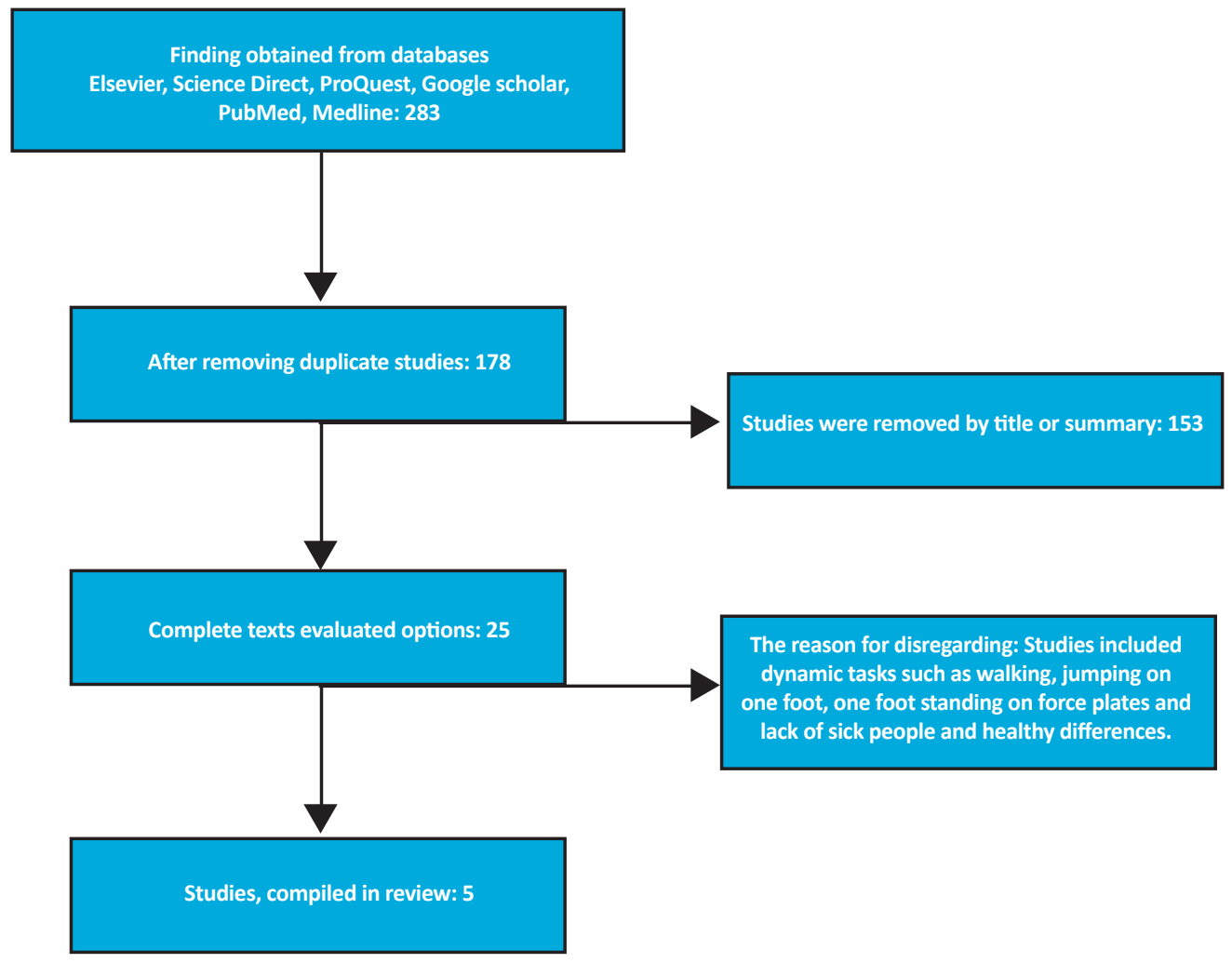

PHYSICAL TREA † MENTS

Figure 1. The study process (PRISMA table). 
during testing, and lack of comparing healthy and sick people. Finally, 5 articles were remained and selected for the study.

\section{Results}

Table 1 presents the summary of the content of these articles.

The CASP scale was used to evaluate the quality of the articles (Table 2).

All available articles studied postural control in patients with knee osteoarthritis. There were 4 studies using variables of COP for evaluating postural control. Force plate was used for evaluating in 5 studies, also in 4 studies, tests were done with open and closed eyes, and in one study measuring was done by closed eye, only. According to the findings, in 3 studies, the patients had more postural fluctuations and less stability with closed and open eyes, particularly closed eyes, compared to healthy subjects. However, in 2 studies, distinctive results were reported. There was no significant difference in balance parameters between patients with osteoarthritis and healthy subjects. Therefore, that displacement was similar in patients compared to the healthy group and there was no statistically significant difference.

\section{Discussion}

The purpose of the study was a systematic review of previous related studies which have examined the differences in COP between patients with osteoarthritis and healthy subjects. The result of these studies revealed that the patients with osteoarthritis demonstrated an increase in fluctuation of COP and the range of these differences can be shown in specific percentages in postural fluctuations. However, there was just one thorough report. With regard to vision, increasing COP parameters in closed eyes condition compared to open eyes were reported which these support defects of proprioception in these patients. There is a report of disorder in sensory input from muscles and joints in closed eyes condition. The initial vision is considered as a controlled low-frequency noise which occurs in two legs standing [19]. In patients with a reduction in pro-

Table 1. Summary of the articles contents.

\begin{tabular}{|c|c|c|c|c|c|c|}
\hline $\begin{array}{c}\text { Author/publish } \\
\text { date }\end{array}$ & Number of people & $\begin{array}{l}\text { Severity of } \\
\text { osteoporosis }\end{array}$ & $\begin{array}{c}\text { Main examined } \\
\text { criteria }\end{array}$ & $\begin{array}{l}\text { Task of } \\
\text { move }\end{array}$ & $\begin{array}{l}\text { Terms of } \\
\text { vision }\end{array}$ & Conclusion \\
\hline Duffell (2014) & $\begin{array}{l}18 \text { People with early } \\
\text { osteoarthritis in one } \\
\text { side of the knee and } 18 \\
\text { healthy subjects }\end{array}$ & Slight & $\begin{array}{c}\text { Mediolateral } \\
\text { displacement and } \\
\text { anterior-posterior } \\
\text { direction }\end{array}$ & $\begin{array}{l}\text { Two legs } \\
\text { standing } \\
\text { on force } \\
\text { plate for } 30 \\
\text { seconds }\end{array}$ & $\begin{array}{l}\text { Open } \\
\text { eyes and } \\
\text { closed } \\
\text { eyes }\end{array}$ & $\begin{array}{l}\text { Displacement was similar in two } \\
\text { groups with open and closed eyes. } \\
\text { The differences were not statisti- } \\
\text { cally significant.Third displacement } \\
\text { was more in the patient group rela- } \\
\text { tion to healthy group in a standing } \\
\text { on one leg. }\end{array}$ \\
\hline Lyytinen (2010) & $\begin{array}{l}54 \text { Patients with osteo- } \\
\text { porosis and } 53 \text { healthy } \\
\text { subjects }\end{array}$ & $\begin{array}{l}\text { Osteoporosis } \\
\text { with Kellgren } \\
\text { Lawrence 1-4 } \\
\quad \text { grade }\end{array}$ & $\begin{array}{l}\text { Speed in me- } \\
\text { diolateral and } \\
\text { anterior-posterior } \\
\text { direction } \\
\text { Sway area }\end{array}$ & $\begin{array}{l}\text { Two legs } \\
\text { standing } \\
\text { on force } \\
\text { plate for } 30 \\
\text { seconds }\end{array}$ & $\begin{array}{l}\text { Open } \\
\text { eyes and } \\
\text { closed } \\
\text { eyes }\end{array}$ & $\begin{array}{l}\text { No statistical difference was ob- } \\
\text { served between osteoporosis and } \\
\text { healthy subjects with regard to the } \\
\text { parameters of balance and there } \\
\text { was no statistical difference between } \\
\text { osteoporosis subgroups (1-4). }\end{array}$ \\
\hline Hassan (2001) & $\begin{array}{l}77 \text { Patients with osteo- } \\
\text { porosis ( } 58 \text { females and } \\
19 \text { males) and } 63 \text { healthy } \\
\text { subjects ( } 45 \text { females and } \\
18 \text { males) }\end{array}$ & $\begin{array}{l}\text { Osteoporosis } \\
\text { and radiographic } \\
\text { evidence of at } \\
\text { least one com- } \\
\text { partment of the } \\
\text { knee }\end{array}$ & $\begin{array}{l}\text { Postural control } \\
\text { fluctuation in } \\
\text { both internal- } \\
\text { external and } \\
\text { external-anterior } \\
\text { direction }\end{array}$ & $\begin{array}{l}\text { Two legs } \\
\text { standing } \\
\text { on force } \\
\text { plate for } 30 \\
\text { seconds }\end{array}$ & $\begin{array}{l}\text { Closed } \\
\text { eyes }\end{array}$ & $\begin{array}{c}\text { People with osteoporosis showed } \\
\text { more postural control fluctuationin } \\
\text { both internal-external and external- } \\
\text { anterior direction }\end{array}$ \\
\hline Wegener (1997) & $\begin{array}{l}11 \text { Patients with bilateral } \\
\text { osteoarthritis and } 10 \\
\text { healthy subjects }\end{array}$ & $\begin{array}{l}\text { With an orthope- } \\
\text { dic diagnosis }\end{array}$ & $\begin{array}{l}\text { Mediolateral and } \\
\text { anterior-posterior } \\
\text { displacement } \\
\text { direction }\end{array}$ & $\begin{array}{l}\text { Two legs } \\
\text { standing } \\
\text { on force } \\
\text { plate for } 10 \\
\text { seconds }\end{array}$ & $\begin{array}{l}\text { Open } \\
\text { eyes and } \\
\text { closed } \\
\text { eyes }\end{array}$ & $\begin{array}{l}\text { Body sway more at all conditions } \\
\text { compared to the control group } \\
\text { increased More body sway was seen } \\
\text { in all conditions compared to the con- } \\
\text { trol group. Body sway increased with } \\
\text { eyes closed with your eyes closed. }\end{array}$ \\
\hline Hurly (1997) & $\begin{array}{l}103 \text { Patients with knee- } \\
\text { osteoarthritis and } 25 \\
\text { healthy subjects }\end{array}$ & $\begin{array}{l}\text { Radiographic } \\
\text { evidence of } \\
\text { osteoporosis }\end{array}$ & $\begin{array}{l}\text { Estimates of the } \\
\text { vertical displace- } \\
\text { ment of the } \\
\text { center of gravity }\end{array}$ & $\begin{array}{l}\text { Two legs } \\
\text { standing } \\
\text { on force } \\
\text { plate for } 10 \\
\text { seconds }\end{array}$ & $\begin{array}{l}\text { Open } \\
\text { eyes and } \\
\text { closed } \\
\text { eyes }\end{array}$ & $\begin{array}{l}\text { The patients have less stability than } \\
\text { control group in the phase of open } \\
\text { eye and closed eye. }\end{array}$ \\
\hline
\end{tabular}


Table 2. Critical appraisal skills programme (CASP) scale.

\begin{tabular}{|c|c|c|c|c|c|}
\hline CASP scale & Duffell (2014) & Lyytinen (2010) & Hassan (2001) & Wegener (1997) & Hurly (1997) \\
\hline Clearly focused question & + & + & + & + & + \\
\hline Appropriate design & + & + & + & + & + \\
\hline Appropriate recruitment & - & + & - & - & - \\
\hline Matched control & + & + & + & + & - \\
\hline Test procedure clearly described & + & + & + & + & + \\
\hline Appropriate outcomes used & - & + & + & - & - \\
\hline Outcome accurately measured to minimize bias & - & + & + & + & - \\
\hline Confounding factors accounted & + & + & + & + & + \\
\hline Appropriate analysis & - & + & + & + & - \\
\hline Precise statistical results presented & - & + & + & + & - \\
\hline Ability to generalize results & + & + & + & + & + \\
\hline Interpretation related to the existing evidence & + & + & + & + & + \\
\hline Total score & 7 & 12 & 11 & 10 & 6 \\
\hline
\end{tabular}

prioceptive input (which is seen in osteoarthritis patients), more attention to visual and vestibular system for maintaining postural stability is required. Thus, vision impairment affects balance deeply. Anterior-posterior and lateral fluctuations were seen in patients with osteoarthritis. It can be considered as a compensatory mechanism to improve the sensory differentiation, which is used in case of damaged feedback loop.

Hirata, in his study, examined evaluation of different sensory conditions to see how severity of structural damage (such as narrowing of the joint space and osteophytes) in knee joint and pain can affect postural fluctuations. In this study, the group with severe symptoms showed increasing external-internal fluctuations, in condition of closed eyes on flat surface, comparing with the group with mild symptoms. So pain severity is related to higher postural fluctuations (the range of COP in internal-external direction), as they stand on flat surface with closed eyes [12].

To further previous studies, Hirata examined those patients with a range of symptoms of pain and structural changes. The result showed increase in postural fluctuations (speed and range of the anterior-posterior direction) on a flat surface in patients with osteoporosis suffering from severe or mild symptoms and with closed eyes. These results suggest that visual database plays an important role for controlling balance in these patients [12].
Increasing body fluctuations in both directions suggests that in patients with osteoporosis the risk of falling is greater when vision and surface database are not ideal. Although there is no identified sensory information in these patients, in the average level of pain, it seems that vision database increases their balance control, because there is a positive relation between pain severity and postural fluctuations (range of COP in internal-external direction) along a flat surface with closed eyes. Previous studies indicate that structural damage of knee join in patients disrupts the sense of position due to knee proprioceptive changes in the brain. This reason can explain why those patients with more severe symptoms showed more internal-external directed postural fluctuations compared to the patients with moderate symptoms [12]. Similar increase in internal-external directed postural fluctuations has been reported in patients who were studied by Hassan [9]. Masui showed that morphological changes in bones such as narrowing the joint space and the existence of osteophytes in knee were important factors for increasing postural fluctuation [15].

Wegener and Hinman found out that patients with osteoarthritis have more postural fluctuations compared to control group in both open and closed eye mode [16]. On the other hand, Hurly reported increase in postural fluctuations just in open eye mode. We can attribute these contradictory results to different evaluation in measuring the balance. Hurly's method of determining stability 
was finding the average of displacement angle vertically, which was different from Wegner and Hinman's measuring of motion of COP [18].

It seems that there are many factors related to knee osteoarthritis and postural stability. These people showed some power cuts and reduction of knee proprioception. Slowing of reaction time and muscle weakness is followed by increase in postural fluctuations. Increasing varus and valgus knee instability can lead to increase in postural fluctuations. Balance instruction can improve postural stability; there were reports of up to $25 \%$ decrease in falling risk in sports, which focus on instructing balance. Hassan pointed out that patients with osteoarthritis and control group were different in weights and strength to weight ratio of their quadriceps. It seems that these distinctions, beside sore knee, are important factors for explanation of higher postural fluctuation in patients with knee osteoarthritis. In fact, in these patients, $30 \%$ of postural fluctuation is attributed to the strength to weight ratio of quadriceps and the pain. Therefore, the muscular weakness caused by osteoarthritis, secondary muscular dysfunction to pain, and the effect of gaining weight help decrease muscle ability for holding postural stability. As a result, frequency of fluctuations will increase [9].

Those 2 studies showed no differences in balance factors between healthy subjects and patients. As Lyytinen et al. showed, there was no difference between healthy subjects and patients with osteoarthritis with regard to postural control [16]. These results opposed the previous results reporting an increase in postural fluctuations in these patient. Perhaps that is why the difference was noted in the evaluation of balance. In this study, the experiment was done 3 times with open eyes and 3 times with closed eyes for an interval of 30 seconds. Subjects were instructed before the experiments and practiced the test several times to increase their accuracy, while they were using the special balance systems twice for 10 seconds.

Duffel showed that the displacement of COP in two legs standing mode on force plate was similar in open eyed and closed eyed subjects; i.e. there was no statistically significant difference between them [10]. One of the limitations of this study was unavailability of some articles in fulltext, so they were eliminated from the experiment. The other limitation was failure to access to all databases.

A systematic review of previous studies showed that patients with knee osteoarthritis showed more postural instability than healthy people. This difference was more prominent in closed eye mode and can be attributed to the phenomenon of controlling pain, loss of proprioception, and muscle weakness.

Studying previous works in examining postural stability between healthy subjects and patients with osteoarthritis has created a bright perspective on the rehabilitation and treatment of patients, and subsequent studies can be complementary in this field.

According to the reviewed studies, we can conclude that postural stability is disrupted in patients with osteoarthritis. Therefore, in clinical treatment of these patients, we should administer pain relief protocols and appropriate interventions for improving their postural stability. We also should consider it as an important part of their treatment.

\section{Acknowledgments}

This paper was extracted from the first author' MSc. thesis. The researchers really appreciate their partners at University of Welfare and Rehabilitation Department of Physical Therapy who helped them during this project.

\section{Conflict of Interests}

The authors declared no conflict of interests.

\section{References}

[1] Gatev P, Thomas S, Kepple T, Hallett M. Feedforward ankle strategy of balance during quiet stance in adults. Journal of Physiology. 1999; 514(3):915-28.

[2] Della Volpe R, Popa T, Ginanneschi F, Spidalieri R, Mazzocchio R, Rossi A. Changes in coordination of postural control during dynamic stance in chronic low back pain patients. Gait \& Posture. 2006; 24(3):349-55.

[3] Baratto L, Morasso PG, Re C, Spada G. A new look at posturographic analysis in the clinical context: sway-density versus other parameterization techniques. Motor Control. 2002; 6(3):246-70

[4] Cash JE. Cash's Text book of orthopaedies and rheumatology for physiotherapist. Missouri: Mosby; 1984

[5] Baliunas AJ, Hurwitz DE, Ryals AB, Karrar A, Case JP, Block $\mathrm{JA}$, et al. Increased knee joint loads during walking are present in subjects with knee osteoarthritis. Osteoarthritis and Cartilage. 2002; 10(7):573-79.

[6] Kirkley A, Webster-Bogaert S, Litchfield R, Amendola A. The effect of bracing on varus gonarthrosis. Journal of Bone and Joint Surgery. 1999; 81(4):539-48.

[7] Bopf DP, McAuliffe M, Shillington M, Drynan D, Bucknell E. Osteoarthritis of the knee: use of investigations and non- 
operative management in the Australian primary care setting. Australasian Medical Journal. 2010; 3(3):194-97.

[8] Felson DT, Zhang Y. An update on the epidemiology of knee and hip osteoarthritis with a view to prevention. Arthritis \& Rheumatism. 1998; 41(8):1343-355.

[9] Hassan BS, Mockett S, Doherty M. Static postural sway, proprioception, and maximal voluntary quadriceps contraction in patients with knee osteoarthritis and normal control subjects. Annals of the Rheumatic Diseases. 2001; 60(6):612-28.

[10] Duffell LD, Southgate DF, Gulati V, McGregor AH. Balance and gait adaptations in patients with early knee osteoarthritis. Gait \& Posture. 2014; 39(4):1057-061.

[11] Sørensen RR, Jørgensen MG, Rasmussen S, Skou ST. Impaired postural balance in the morning in patients with knee osteoarthritis. Gait \& Posture. 2014; 39(4):1040-044.

[12] Hirata RP, Jørgensen TS, Rosager S, Arendt-Nielsen L, Bliddal $\mathrm{H}$, Henriksen $\mathrm{M}$, et al. Altered visual and feet proprioceptive feedbacks during quiet standing increase postural sway in patients with severe knee osteoarthritis. PloS One. 2013; 8(8):e71253. doi: 10.1371/journal.pone.0071253

[13] Lyytinen T, Liikavainio T, Bragge T, Hakkarainen M, Karjalainen PA, Arokoski JP. Postural control and thigh muscle activity in men with knee osteoarthritis. Journal of Electromyography and Kinesiology. 2010; 20(6):1066-074.

[14] Tarigan TJ, Kasjmir YI, Atmakusuma D, Lydia A, Bashiruddin J, Kusumawijaya K, et al. The degree of radiographic abnormalities and postural instability in patients with knee osteoarthritis. Acta Med Indones. 2009; 41(1):15-9.

[15] Masui T, Hasegawa Y, Yamaguchi J, Kanoh T, Ishiguro N, Suzuki S. Increasing postural sway in rural-communitydwelling elderly persons with knee osteoarthritis. Journal of Orthopaedic Science. 2006; 11(4):353-58.

[16] Wegener L, Kisner C, Nichols D. Static and dynamic balance responses in persons with bilateral knee osteoarthritis. Journal of Orthopaedic \& Sports Physical Therapy. 1997; 25(1):13-18.

[17] Kim HS, Yun DH, Yoo SD, Kim DH, Jeong YS, Yun JS, et al. Balance control and knee osteoarthritis severity. Annals of Rehabilitation Medicine. 2011; 35(5):701-09.

[18] Hurley MV, Scott DL, Rees J, Newham DJ. Sensorimotor changes and functional performance in patients with knee osteoarthritis. Annals of the Rheumatic Diseases. 1997; 56(11):641-48.

[19] Gill J, Allum JH, Carpenter MG, Held-Ziolkowska M, Adkin AL, Honegger F, et al. Trunk sway measures of postural stability during clinical balance tests: effects of age. Journal of Gerontology Series A: Biological Sciences and Medical Sciences. 2001; 56(7):438-47 
